\title{
Fitha

\section{O aprender e o ensinar a partir da obra Que é uma coisa?, de Martin Heidegger}

\author{
Learning and teaching from Martin Heidegger's What's a Thing?
}

\begin{abstract}
Adma Emanuelle Gama
Mestranda na Universidade Federal de Alagoas, Maceió, Alagoas, Brasil. adma_gama@hotmail.com - https://orcid.org/0000-0002-2840-7924

Walter Matias Lima

Professor doutor na Universidade Federal de Alagoas, Maceió, Alagoas, Brasil. waltermatias@gmail.com - https://orcid.org/0000-0002-2840-7924
\end{abstract}

Recebido em 01 de maio de 2019

Aprovado em 17 de julho de 2019

Publicado em 09 de outubro de 2019

\section{Resumo}

O presente trabalho, decorrente de uma pesquisa bibliográfica através do método de análise do conteúdo, visa pensar acerca do aprender e do ensinar a partir do princípio matemático, tá mathemata, retomado por Heidegger. Nossa proposta traz como texto base a obra de Heidegger O que é uma coisa? (1935 - 1936). A obra é organizada em duas partes: uma parte preparatória e uma parte principal dividida em dois capítulos. Nosso texto retomará a parte preparatória na qual, Heidegger, através da questão Que é uma coisa?, visa compreender se há um saber que determina os fundamentos e limites da ciência ou se é a ciência o padrão de medida do saber, e também o primeiro capítulo da parte principal, no intuito de abordarmos a discussão acerca do princípio matemático que provém etimologicamente do grego tá mathemata, o que se pode aprender - Manthanoein - e ao mesmo tempo, consequentemente o que se pode ensinar - Mathesis - que significa lição e traz um duplo sentido: ir a uma lição e aprender e aquilo que é ensinado. Matemático é compreendido como um pré-requisito para que se aprenda e ensine acerca de qualquer coisa. Assim, nossa proposta é considerar no princípio grego tá mathemata, como assumido por Heidegger, um ensinar que ressalta a exigência de despertar no estudante o sentido de um autêntico aprendizado ao invés de uma simples transferência de um determinado assunto.

Palavras-chave: Tá Mathemata; Aprender; Ensinar. 


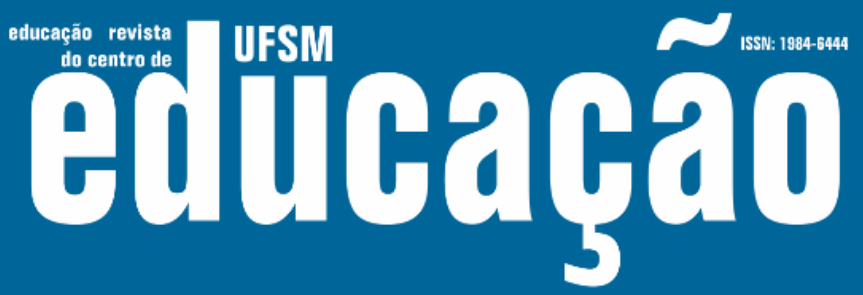

ISSN: 1984-6444 | http://dx.doi.org/10.5902/1984644437922

\section{ABSTRACT}

The present work, derived from a bibliographical research through the method of content analysis, aims to think about learning and teaching from the mathematical principle, tá mathemata, taken up by Heidegger. As the basic text, our proposal takes up Heidegger's work, What is a Thing? (1935-1936). The work is organized in two parts: a preparatory part and a main part divided into two chapters. Our text will take up the preparatory part in which, Heidegger, through the question, "What is a thing?," aims to understand whether there is a knowledge that determines the foundations and limits of science or, rather, if it is Science that is the standard of measurement of knowledge. It will also take up the first chapter of the main part, in order to approach the discussion about the mathematical principle that etymologically derives from the Greek ta mathemata, what can be learned - manthanoein - and at the same time, consequently what can be taught - mathesis - which means lesson and implies a double meaning: receiving a lesson or learning on the one hand and what is taught on the other. Mathematics is understood as a prerequisite for learning and teaching about anything. Thus, our proposal is to consider in the Greek principle tá mathemata, as taken over by Heidegger, teaching by underscoring its requirement to awaken in the student the sense for an authentic learning instead of a simple transference of a certain subject.

Keywords: Tá Mathemata; Learning; Teaching.

\section{Introdução}

Com a finalidade de desobstruir a tradição, que promoveu o esquecimento da pergunta pelo ser, Heidegger, em Ser e tempo (2011), lança uma tarefa que utiliza a hermenêutica para interpretar os filósofos da tradição. "Essa tarefa nós a entendemos como a destruição do conteúdo transmitido pela ontologia antiga, tarefa a ser levada a cabo pelo fio-condutor da questão-do-ser até chegar às experiências originárias em que se conquistaram as primeiras determinações do ser" (HEIDEGGER, 2011, p. 87 grifos do autor). Tal tarefa se completa com os escritos a partir do final dos anos 20 , em que se dá a virada heideggeriana, uma mudança de ênfase que é descrita por Heidegger como uma 'Kehre'. Entretanto, ela não significa uma mudança do seu ponto de vista e muito menos da questão fundamental. A virada: 


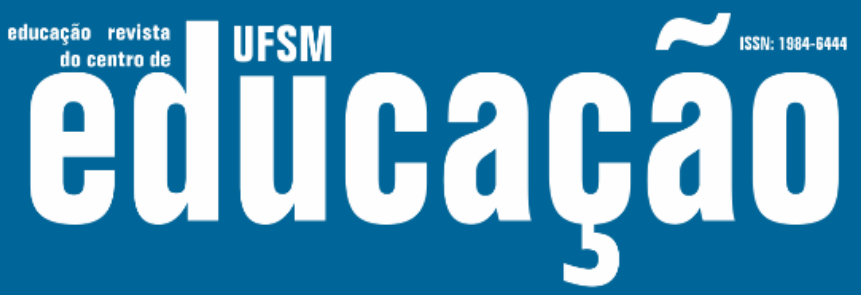

ISSN: 1984-6444 | http://dx.doi.org/10.5902/1984644437922

[...] specifically stresses the importance of the phenomenological notion of truth as unconcealment or unhiddenness. With the question of the truth of be-ing, Heidegger is asking beyond the analogous substrctures of the meaningful open of Dasein to address the unconcealment or openness of this open itself (QUAY, 2015, p. 128). ${ }^{1}$

O que ocorre nessa mudança de ênfase é um deslocamento da questão do significado do ser-aí para a questão da verdade do ser - da questão ser como ser-aí para a questão ser como ser-aí - que também é descrita por Heidegger como do "Ser e Tempo" para "Tempo e Ser". Quay (2015) explica que, as duas ênfases são aspectos de uma única questão feita por Heidegger - a questão do ser. Essas duas ênfases que perguntam pelo mesmo, ao mesmo tempo que são distintas e mostram o Ereignis ${ }^{2}$ de duas ênfases. Ambas são necessárias na investigação de Heidegger, pois a questão da verdade do ser emerge da questão acerca do significado do seraí.

Essa inversão não constitui uma mudança na posição de Ser e Tempo mas é nela que o pensamento aí tentado alcança o lugar da dimensão, a partir da qual se fez a experiência de Ser e Tempo, e se fez a partir da experiência fundamental do esquecimento do Ser (HEIDEGGER, 1995, p. 47).

Com a ênfase acerca da verdade do ser, Heidegger propõe analisar a descontinuidade da physis, silenciada na filosofia tradicional, na qual, a verdade é o veio remanente (NUNES, 1992). Tal questão desemboca na análise acerca do deslocamento da essência da verdade, que ocorre com a interpretação de Platão no mito da caverna. Através dessa interpretação, "a essência da verdade não se desenvolve propriamente como essência do desvelamento a partir da plenitude essencial própria, mas se desloca para a essência da ıঠéa. A essência da verdade abandona o traço fundamental do desvelamento" (HEIDEGGER, 2008b, p. 242).

Consequentemente vemos que a palavra filosofia, que até então era designada para nomear a busca pelo correto ser versado, em Platão, passa a se referir ao ser versado no ente, no qual este é determinado como ideia. Ao interpretar o ser como ideia, o pensar a respeito do ser do ente se transforma em metafísica. Mesmo quando a filosofia é entendida como "crítica", exemplo, Descartes e Kant, ela continua a seguir "[...] a esteira da representação metafísica. Ela pensa a partir do ente e na direção do ente através de uma visão sobre o Ser. Pois já é na luz do Ser 


\section{U usm Eutbapga}

ISSN: 1984-6444 | http://dx.doi.org/10.5902/1984644437922

que sempre se processa todo o movimento a partir do ente, como todo retorno para o ente" (HEIDEGGER, 1995, p. 52). Em Heidegger, a metafísica determina a história da era ocidental, através da qual são estabelecidas as diversas relações entre nós com as coisas, ambos entes, em um mundo entendido como o nosso.

O princípio estruturador do sentido desse mundo, aquilo que confere à totalidade das coisas a condição de mundo, é a metafísica, uma função ou um aspecto de todo e qualquer pensamento (sempre articulado pela linguagem). $O$ pensamento metafísico, ou a metafísica, pura e simplesmente, origina-se em parte, de nossa resposta a necessidades práticas e imediatas, em parte do mistério que é nosso próprio pensamento. Como tal, a metafísica procede a uma esquematização do caos, ainda que não só, porque também consiste em uma espécie de lançamento, através do qual os entes que chamamos homens projetam sobre o ente em seu todo, inclusive eles mesmos, e ainda que de forma alienada, uma certa essência ou um certo princípio de significação (RÜDIGER, 2006, p. 68).

A metafísica ocidental é constituída por dois motivos determinantes: teológico-cristão; matemático (VEIGA, 2011). Ela tornar-se teológica em decorrência da correspondência que Aristóteles faz acerca da ideia suprema, o bem, com o que se irá denominar de divino. "Teologia significa aqui interpretar a "causa" do ente como Deus e deslocar o ser para essa causa, que contém em si e dispensa a partir de si o ser, uma vez que é o que há maximamente ente do ente" (HEIDEGGER, 2008 b, p. 247). Mas também há um outro traço importante na metafísica que é o matemático. Esse já é visto na Introdução a filosofia (1928-1929), curso de inverso que visa discutir: filosofia e ciência e filosofia e visão de mundo. Em que a ciência pertencente a paixão pelo questionar, traz como característica a exatidão no qual esta repousa no seio do matemático. "Uma ciência só é científica na medida em que for matematizável. [...] a matemática se mostra como a ciência propriamente dita, pois é de fato a mais exata das ciências e seus resultados são, de modo puro e simples, universalmente validos" (HEIDEGGER, 2008a, p. 45). Essa é uma compreensão que Heidegger extrai das conclusões de Kant, veremos que:

O matemático se torna um fio condutor importante para os filósofos modernos, mas a sua exposição e utilização "explícitas" ocorrem com Galileu durante o desenvolvimento da física matemática. Heidegger trabalha a ideia do matemático a partir da sua origem grega em uma abordagem etimológica. Mas o objetivo de Heidegger é mostrar a modificação realizada por Galileu frente ao mundo antigo e medieval. Esta modificação implicou uma mudança no modo moderno de compreensão do ser (transformado em 


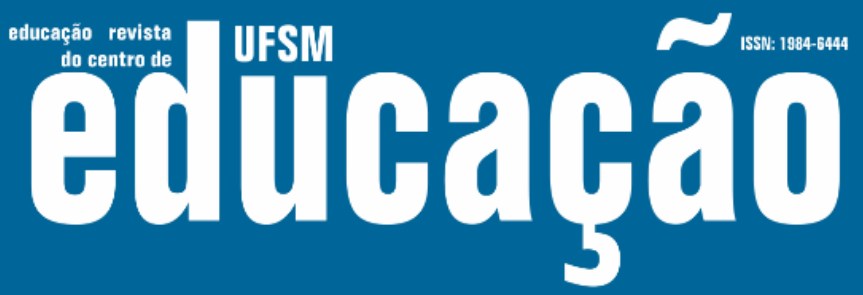

ISSN: 1984-6444 | http://dx.doi.org/10.5902/1984644437922

"natureza") e dos entes (transformados em corpúsculos físicos definidos espaço-temporalmente). Portanto, a compreensão que Galileu imprime à matemática é uma alteração daquilo provém desde a antiguidade, e que se encontrava já em uma constituição original. Galileu modifica a constituição original, gerando uma outra "constituição" determinante, e esta determina todo o conhecimento científico posterior (VEIGA, 2011, p. 40).

Essa modificação implica em uma nova forma de olhar e organizar o ente, "A intelecção epocal de Galileu foi reconhecer que, caso eu queira por meio do experimento, interrogar a natureza quanto ao que ela é e como ela é, já preciso ter antes de tudo um conceito do que compreendo por "natureza"' (HEIDEGGER, 2008a, p. 200). Ou seja, eu já preciso ter a priori uma delimitação acerca do que é "natureza", e isso se dá através do aspecto matemático compreendido pelos gregos. Assim o que irá distinguir a Ciência Moderna, da medieval e a antiga, não será nem a observação dos fatos, visto que, "[...] tanto na Antiguidade quanto na idade Média, já havia uma ciência natural que observava os fatos" (HEIDEGGER, 2008a, p. 199); e nem a questão do experimento pois, "[...] sabemos que a antiga ciência natural também já trabalhava com experimentos e, contudo, não tinha o caráter alcançado pela física por meio de Galileu" (HEIDEGGER, 2008a, p. 200). O aspecto matemático será assim o traço fundamental para a ciência moderna. Heidegger aborda tanto esse como os outros dois aspectos no curso de inverno de (1935/1936), intitulado de O que é uma coisa? Doutrina de Kant dos Princípios Transcendentais. Diante disto, o nosso principal objetivo é pensar o processo de ensino e aprendizagem que envolve professor e aluno, através das contribuições de Heidegger acerca desse aspecto matemático, que estão expostas na primeira parte dessa obra.

\section{A questão, que é uma coisa?}

Heidegger em seu livro Que é uma coisa? (1992), fruto de um curso que coloca uma questão que pertence ao domínio das questões fundamentais da metafísica, a questão do Que é uma coisa? traz múltiplos sentidos classificados como: sentido restrito que refere-se ao que está disponível, o que está ao alcance da mão; sentido lato este é referente aos acontecimentos e eventos; e por fim o 


\section{T usm oltibapat

ISSN: 1984-6444 | http://dx.doi.org/10.5902/1984644437922

sentindo ainda mais lato, neste são incluídos todas as coisas dos outros dois sentidos e também quaisquer outras que sejam algo e não nada. Heidegger explica que em detrimento do nosso atual uso da língua o sentido restrito é o mais fácil para compreendermos a palavra coisa. Além do que, mesmo quando a questão acerca da coisa é entendida em sentido lato ou mais lato de todos, na maioria das vezes ela parte e aponta para o sentido restrito.

Mas ao perguntarmos acerca da coisa em sentido restrito, buscando seguir o conselho da criada que riu do filósofo Talles, "que deveríamos, antes de mais, prestar atenção ao que se passa à nossa volta” (HEIDEGGER, 1992, p. 18). Perceberemos que todas estas já estão há muito tempo determinadas e para as que não estão há modos seguros de proceder e produzir através da ciência. Logo o que Heidegger busca saber está em contraste com relação ao que é dito pela ciência. 0 que ele busca acerca da coisa, não é em relação a sua especificidade, através da qual determinamos por exemplo as plantas isoladas e as espécies de plantas, mas sim, acerca da sua coisalidade, ou seja, aquilo que faz a coisa ser coisa e que é incondicionado. Sua busca não visa desqualificar a ciência e sim pensar acerca da determinação do saber e consequentemente sua relação com a ciência.

Com a nossa questão não podemos nem substituir, nem melhorar as ciências. No entanto, quereríamos colaborar na preparação de uma decisão. Esta decisão é a seguinte: é a ciência o padrão de medida para o saber, ou há um saber no qual, em primeiro lugar, se determinam os fundamentos e os limites da ciência e, com isso a sua eficácia própria? É este saber autêntico necessário a um povo histórico, ou pode passar-se sem ele e substituí-lo por outra coisa? (HEIDEGGER, 1992, p. 21).

Para Heidegger através da questão Que é uma coisa?, será possível compreender se há um saber que determina os fundamentos e limites da ciência ou se é a ciência o padrão de medida do saber. Essa questão não significa um querersaber-mais do que a ciência o que implicaria estar no mesmo âmbito que o da ciência. Mas sim, ela se coloca fora do âmbito das ciências e visa um saber diferente que não é tido nem como superior e nem como inferior. 


\section{Euthaหูão}

ISSN: 1984-6444 | http://dx.doi.org/10.5902/1984644437922

\section{A istidade da coisa}

Partindo da proposta de buscar as coisas a partir de sua coisalidade, se faz necessário então buscar aquilo que pertence a todas as coisas e a cada uma delas, enquanto tais, aquilo que compreendemos como o caráter de istidade. Logo, Heidegger compreende que a singularidade é uma característica das coisas, universal e sem exceção. Além de sua singularidade as coisas são também determinadas, pois "não há uma coisa em geral, mas apenas estas coisas singulares e as singulares, antes de mais, são \{esta coisa\}. Cada coisa é esta coisa e nenhuma outra" (HEIDEGGER, 1992, p. 25). A determinação universal para que uma coisa seja 'esta coisa', ou seja, a istidade da coisa é o fato de sua relação com espaço e tempo. A coisa é esta coisa na medida em que ela e nenhuma outra está em conexão com o espaço e tempo, neste caso, esta coisa se encontra em um determinado lugar e dentro de um determinado momento-de-tempo.

A partir disso eis que surge um novo questionamento espaço e tempo são pertencentes ou exteriores a coisa?. Acerca dessa questão Heidegger busca verificar o fator espaço e tempo no qual ele percebe que aumenta "a impressão de que o espaço e tempo são apenas domínios susceptíveis de acolher as coisas, indiferentes a elas, mas utilizáveis para Ihes atribuir um lugar espácio-temporal" (HEIDEGGER, 1992, p. 31). Resultando, aqui, a dúvida se as coisas são de maneira inconfundível 'esta coisa' quando a examinamos a partir dela mesma. Para esclarecimento busca-se aferir acerca do pronome demonstrativo Isto, se ele nos diz algo acerca da coisa. No Isto está presente um indicar, um mostrar, um instruir algo a alguém. Essa instrução está no âmbito do aí - o aí, isto aí, enquanto que o aquilo está no âmbito do ali - aquilo ali. Assim tanto isto quanto o aquilo se encontram no nomear de cada coisa, na medida em que são utilizados para indicar uma determinada coisa. Não conferindo ao isto ser uma característica da própria coisa e sim, um acréscimo subjetivo introduzido pelo homem no ato de indicar uma determinada coisa. No entanto esse acréscimo também depende da coisa que vem ao nosso encontro. No qual também estamos implicados assim como a coisa em um determinado tempo e espaço. 


\section{N

ISSN: 1984-6444 | http://dx.doi.org/10.5902/1984644437922

Começamos com a afirmação: as coisas à nossa volta são coisas particulares são sempre 'estas coisas'. Com esta última caracterização atingimos o domínio de indicação das coisas ou, inversamente, o domínio do modo como as coisas nos encontram. 'Indicação' e 'encontro': isto significa, em geral, o domínio em que também nós, os pretensos 'sujeitos', nos encontramos. Se queremos conceber este domínio, encontramos sempre o espaço e o tempo; a esse domínio que circunda as coisas e que se manifesta sempre através da necessidade de nos referirmos ao espaço e ao tempo, chamamos espaço-tempo, que possibilita a indicação e o encontro (HEIDEGGER, 1992, p. 39)

O próximo passo é sair desse domínio em que as coisas vêm ao nosso encontro e buscar uma representação acerca da maneira que as coisas são constituídas, observando exclusivamente para a estrutura da coisa.

\section{Concepção natural do mundo: a coisa como suporte}

Heidegger chega ao entendimento que sempre uma coisa é constituída de propriedades e de uma determinada maneira, no qual a coisa na verdade é um suporte em que estas propriedades se apoiam e assim qualquer coisa traz em si outras coisas. "As coisas atuam uma sobre as outras e opõem-se umas às outras; de tais relações entre as coisas resultam, depois, outras propriedades, que as coisas passam igualmente a ter" (HEIDEGGER, 1992, p. 41).

Essa caracterização da coisa e de como ela se relaciona é chamada de 'concepção natural do mundo'. Acerca dessa concepção de coisa já traziam a filosofia de Platão e principalmente a de Aristóteles e por fim encontramos na filosofia de Kant. Mesmo em concepções filosóficas diferentes e trazida com diferentes palavras e outros conceitos, o entendimento é que "uma coisa é o suporte subsistente de diversas propriedades, que nela subsistem e se modificam" (HEIDEGGER, 1992, p. 41). Essa concepção domina todo o pensamento científico no que tange não só o âmbito teórico, mas também todo o comércio com as coisas, o seu cálculo e a sua avaliação. E as designações conhecidas e usuais da determinação tradicional da coisalidade da coisa, segundo Heidegger (1992), pode ser fixada da seguinte maneira: Fundo, compreendido como o que está sempre já aí, o que também já se manifestou; Substantia - accidens; Suporte - propriedades; e, Sujeito - predicado. 


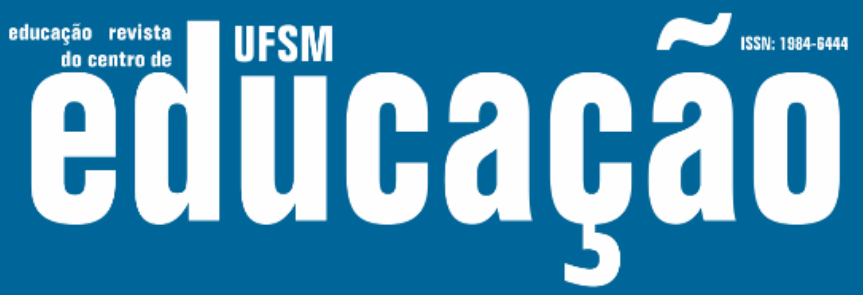

ISSN: 1984-6444 | http://dx.doi.org/10.5902/1984644437922

A determinação da coisa está também fundamentada e é a todo momento possível de fundamentar na sua verdade. A fundamentação dessa verdade reside na própria essência da verdade, que é a conformidade com as coisas. "A partir da essência da verdade como conformidade, torna-se necessário que a estrutura da verdade seja um reflexo da estrutura da coisa" (HEIDEGGER, 1992, p. 42). Dessa mesma compreensão é possível verificarmos se algo é verdadeiro ou falso, no qual está se dá através da análise do enunciado. Os enunciados têm um caráter triplo no qual através de uma proposição transmitimos uma informação a alguém o que acarreta em uma comunicação. A verificação de sua verdade se dá através da conformidade desse enunciado com a coisa pela qual foi comunicada através dele.

Heidegger parte da ideia de que o natural tem sempre um caráter histórico. Assim, quando nos referimos às coisas como um suporte de propriedades temos como referência a determinação de coisa já estabelecida por uma tradição antiga histórica, no qual o questionar pela coisa tem um caráter histórico. O modo de questionar sobre a coisa teve diversas alterações no decorrer dos séculos apesar de nenhuma ser decisiva segundo Heidegger. Na busca pela qualificação da coisa, ou seja, o que faz a coisa ser coisa é visto que busca-se pelo incondicionado. Mas, é visto que durante séculos a essência do incondicionado é determinada através daquilo que consideramos como coisa e condição.

\begin{abstract}
Quando a coisa vale como ens creatum, como um subsistente criado por Deus, então o incondicionado é Deus, no sentido do Antigo Testamento. Quando a coisa vale como aquilo que está diante do Eu, como objeto, quer dizer, como não-eu, então o incondicionado é o Eu, o Eu Absoluto, no sentido do Idealismo Alemão. O fato do incondicionado ser procurado por cima, ou por trás, ou nas costas, depende do que se entende por condição e por ser-condicionado (HEIDEGGER, 1992, p. 53).
\end{abstract}

Ao questionar historicamente pelo que é uma coisa?, Heidegger tem o intuito de colocar em movimento o acontecer inicial da questão, que por muito tempo esteve parado. Para ele o que se diz do caráter histórico da questão acerca da coisa, é válido para qualquer questão de filosofia que possa ser colocada hoje ou no futuro. Devido ao fato dele entender que "a filosofia é um questionar que se põe a si mesmo em questão e que, em consequência, se movimenta, sempre e em toda a parte, em círculo" (HEIDEGGER, 1992, p. 54). 


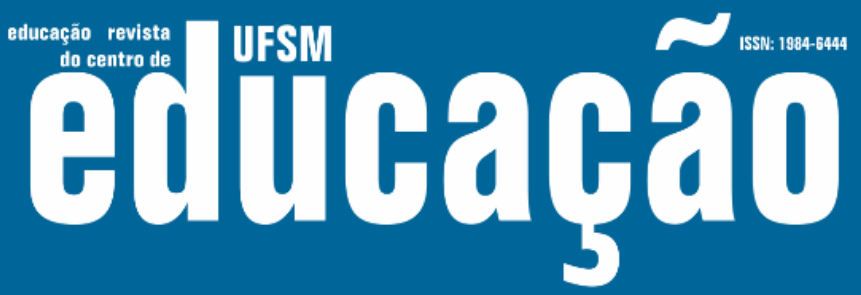

ISSN: 1984-6444 | http://dx.doi.org/10.5902/1984644437922

A resposta para a questão acerca da coisa é uma posição-de-fundo que inicia a transformação do modo como nos colocamos diante das coisas, a maneira que como nos colocamos no questionar, no avaliar, no ver e no decidir. Para tal transformação é necessário observar a maneira de se relacionar com o Ente, que é consolidada pela moderna ciência da natureza, visto que esta se tornou a forma geral do saber. Assim nesse pôr-se a investigar acerca da coisa, Heidegger traz a interpretação filosófica de Kant acerca da coisalidade da coisa, por entender que:

A filosofia de Kant traz, pela primeira vez, para a claridade e a transparência de uma fundamentação, a totalidade do pensar e do estar-aí modernos. Desde então, tal fundamentação determina toda a postura do saber: a delimitações e os cálculos das ciências, do século XIX até ao presente (HEIDEGGER, 1992, p. 63).

O título da obra Crítica da Razão Pura de Kant, segundo Heidegger exprime a coisa como questão. Ele parte do entendimento que a razão é a tradução de lógos e ratio, ambos entendido como um enunciado. E como vimos anteriormente que de acordo com a tradição a coisa é um suporte e que é através do enunciado que podemos dizer qualquer coisa acerca de qualquer outra coisa. Assim a crítica proposta por Kant é acerca do modo como visamos a coisa e pensamos algo sobre ela.

Heidegger nos explica que a transformação da ciência sempre se dará através da própria ciência, mas que essa transformação tem como base um duplo fundamento que são na experiência-do-trabalho e na metafísica, que encontram-se numa relação de reciprocidade. A ciência moderna irá diferenciar da antiga e medieval devido a maneira e o procedimento pelo qual os fatos e os conceitos são concebidos e avaliados. Essa ciência traz três características: ela é entendida como ciência dos fatos, ela é experimental e por fim ela é uma ciência investigativa que calcula e mede. Mas Heidegger explica que todos essas características são de certo modo encontradas nas ciências antigas e que essas características não determinam o traço fundamental da nova posição do saber. Este traço é fundamental se dá na matemática. 


\section{U usm Alltapato

\section{Matemático como pré requisito para ensinar e aprender}

Heidegger traz a matemática como configuração do matemático, nesse sentido o matemático que provém etimologicamente do grego "tá mathemata", o que se pode aprender - Manthanoein - e o mesmo tempo, consequentemente o que se pode ensinar - Mathesis - que significa lição e traz um duplo sentido: ir a uma lição e aprender e aquilo que é ensinado. $O$ aprender e o ensinar são compreendidos em um sentido lato e essencial, assim, não pode ser entendido em sentido restrito e tardio, como é utilizado na escola. Matemático é compreendido como um prérequisito para que se aprenda e ensine acerca de qualquer coisa.

Segundo Heidegger (1992), há determinações que foram empregados pelos gregos com sentido matemático, a saber: (1) Ta Фuбıкá, (física) as coisas físicas; (2)

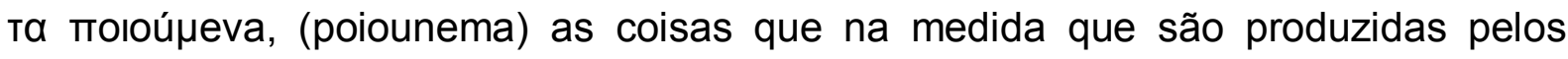

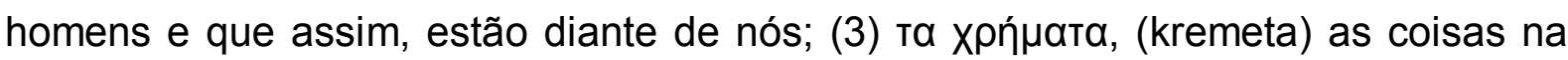

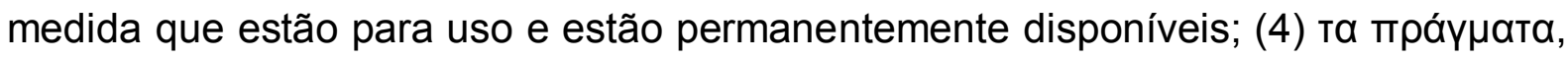
(pragmata) as coisas uteis e práticas para utilizarmos, transformarmos ou apenas

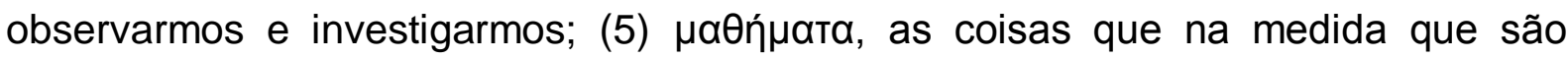
coisas podem ser aprendidas. Segundo Kohanski (1984), nestas cinco maneiras gregas de se conhecer as coisas retomadas por Heidegger, podemos ver uma certa ordem crescente de abstração da percepção sensorial, ou níveis de separação entre forma e conteúdo. Ele explica que:

In the physical state, things are know as they are under natural conditions of observation: form and content are taken together as one objective reality. In the poiounema, the content is a natural stuff but the form is man-made. In the chremata, the content predominates insofar as it is an object of use. In the pragmata, the form stands out as human activity but dealing with a content for pratical purposes or contemplation. In all these four states a thing is delimited objectively as to its form and content, at first undifferentiated but later differentiated in various degrees. In the last state, that is, in the mathemata or axiomata, things lose their content entirely and the human mind is preoccupied with pure forms interrelated among themselves. This kind of knowledge of things is rational to the highest degree, especially when the relationships are expressed in statements of numerical ratios, which is the main feature of the ratiocination of modern science (KOHANSKI, 1984, p. $126)^{3}$. 


\section{F HWM Eulloahâ}

ISSN: 1984-6444 | http://dx.doi.org/10.5902/1984644437922

Nessas determinações empregadas pelos gregos há uma relação no sentido lato que incluído todo o fazer, exercitar e suportar; e por fim por estarem posta de um certo modo, numa determinada perspectiva. $\mathrm{O}$ matemático no contexto grego traz dois sentidos: "em primeiro lugar, o que pode aprender do modo já referido e somente desse modo; em segundo lugar o modo do próprio do aprender e do proceder" (HEIDEGGER, 1992, p. 81). Assim o matemático remete ao "que há manifesto nas coisas, em que sempre nos movimentamos e de acordo com o qual as experimentamos como coisas e como coisas de tal gênero" (HEIDEGGER, 1992, p. 81).

Heidegger explica que estamos habituados a pensar o matemático a partir dos números, apesar de que, eles estão em conexão. Essa conexão reside do fato de "o número tem uma tal essência que ele se pode aprender". (HEIDEGGER, 1992, p. 81). O aprender é definido como um "modo do apreender e do apropriar-se". Mas, Heidegger explica que "[...] nem todo tomar é um aprender. [...] $<<$ Tomar $>>$ significa entrar na posse de alguma coisa, de qualquer modo, e dispor dela" (HEIDEGGER, 1992, p. 77). O tomar que implica em um aprender se dá através do uso, que implica em um exercício. Assim, o exercício é um modo de aprender através dele. Mas ele é apenas um modo pois, "Nem todo o aprender é um exercitar-se" (HEIDEGGER, 1992, p. 77).

Para esclarecer a real essência do aprender, o filósofo remete ao exemplo da arma na qual a utilização desta implica que "[...] o nosso modo de proceder e de nos relacionarmos se ajusta àquilo que a própria arma exige" (HEIDEGGER, 1992, p. 78). Essa relação de aprender acerca de algo exige de antemão conhecer aquilo que iremos manusear. "O aprender é também, sempre, um aprender a conhecer. No aprender, há sempre uma direção do aprender, aprender a utilizar, aprender a conhecer. Por sua vez o aprender a conhecer tem diferentes graus" (HEIDEGGER, 1992, p. 78).

Acerca dos diferentes graus do aprender a conhecer, há o aprender acerca de algo determinado de maneira singular e específica e há o aprender a conhecer algo de maneira geral, indeterminada. Através do exercício aprendemos "[...] apenas uma parcela limitada do que há para aprender numa coisa. O aprender originário é 


\title{
T WsM Eutoraba
}

ISSN: 1984-6444 | http://dx.doi.org/10.5902/1984644437922

aquele tomar em que tomamos o conhecimento daquilo que em geral uma coisa é em cada caso" (HEIDEGGER, 1992, p. 79).

Quando esse conhecimento antecipado de modo geral e indeterminado sobre qualquer coisa, é trazido à tona, no momento em que nos predispomos a saber acerca de alguma coisa de modo específico e determinado, então tomamos conhecimento de que já possuímos um conhecimento antecipado. O "tomar conhecimento" de que já sabemos de um modo antecipado é, segundo Heidegger. a essência autêntica do conhecer. "Este verdadeiro aprender é, por consequência, um tomar peculiar, um tomar no qual aquele que toma, toma, no fundo, aquilo que já tem." (HEIDEGGER, 1992, p. 79).

Heidegger afirma que a este aprender também condiz o ensinar. No ato de ensinar não é dado ou oferecido o ensinável, mas sim uma indicação ao aluno para que próprio possa vivenciar o seu "tomar conhecimento" acerca do conhecimento que ela já possui. Assim, ensinar requer despertar no aluno um sentido para sua aprendizagem e não simplesmente a transferência de um determinado assunto, fazse necessário que o que será aprendido pelo aluno seja algo que lhe traga alguma significância e necessidade por ele reconhecida, atribuindo para si um sentido próprio. Pois "quando o aluno recebe apenas qualquer coisa de oferecido, não aprende" (HEIDEGGER, 1992, p. 79). O filósofo compreende que o verdadeiro aprender implica em que ao tomar conhecimento daquilo que já se tem o aluno possa experimentar um "dar a si mesmo" (HEIDEGGER, 1992, p. 79).

\begin{abstract}
Heidegger aponta que o ensinar/aprender dá-se em um tipo de relação com as mathematas, capaz de estabelecer uma identidade entre quem aprende e o que é aprendido. É isso que o filósofo quer dizer quando afirma que o ensinar é indicar a quem deseja aprender aquilo que já se tem. Daí, a tarefa premente de quem ensina (do docente), quando se trata de conteúdos, é oferecer a oportunidade de o aluno reconhecer em si essa identidade fundamental e como a mesma se dá. Pois ensinar, segundo Heidegger, nada mais é do que provocar o aluno a descobrir um sentido próprio a si e a própria necessidade do seu aprender (KAHLMEYER-MERTENS, 2008, p. 39).
\end{abstract}

Tal proposta traz a concepção do ensinar/aprender como uma tarefa que proporciona ao aluno um exercício de investigação que remete em uma aprendizagem significativa para sua existência. "A aprendizagem significativa 


\section{T WFM Futlagha}

ISSN: 1984-6444 | http://dx.doi.org/10.5902/1984644437922

consiste igualmente em adquirir conhecimentos e em aprender a pensar." (REZENDE, 1990, p. 52). Na obra O que quer dizer o pensar? (2001), Heidegger expõe o ensinar como "deixar aprender", no qual o homem "visto como um ente pode pensar" (Heidegger, 2001, 111), e que, "aprende à medida que traz todos os seus afazeres e desfazeres para a correspondência com isso que a ele é dito de modo essencial. Aprendemos a pensar à medida que voltamos nossa atenção para o que cabe pensar cuidadosamente" (HEIDEGGER, 2001, 112).

O aprender é colocado como a tarefa mais difícil, no que tange aquilo que Heidegger define como aprender verdadeiramente e seu pressuposto fundamental é o matemático. Esse pressuposto já é colocado por Platão na entrada de sua Academia a frase que diz: "Ninguém pode ter aqui entrada, senão tiver compreendido o matemático" (HEIDEGGER, 1992, p. 82). Conforme Heidegger explica, esta frase não significa que aquele que entrar na Academia de Platão deve ser geômetra, no sentido de ser formado em um disciplina especifica acerca disto, mas sim que deve possuir condições-de-fundo para um poder-saber adequado. Esse é o sentido de geômetra, ou seja:

\footnotetext{
O matemático no sentido original do aprender-a-conhecer aquilo que já se conhece, é o pressuposto fundamental do trabalho <<acadêmico >>. Por isso, esta frase, posta à entrada da Academia, contém nada mais nada menos que uma rigorosa condição de trabalho e uma clara delimitação do trabalho" (HEIDEGGER, 1992, p. 82).
}

O poder-saber implica a possibilidade de se poder ensinar, não há ensino se não houver um aprendizado verdadeiro. Antes de ser um professor é preciso ser um aluno e ele "[...] diferencia-se do aluno somente porque pode aprender melhor e quer aprender mais autenticamente. Em todo o ensinar é o professor quem mais aprende" (HEIDEGGER, 1992, p. 80).

Nesse exercício de conduzir o aluno o docente também aprende. O que diferencia a aprendizagem do docente para a do aluno é que o primeiro tem de maneira mais clara que o segundo, mas a dificuldade em aprender é a mesma dificuldade do ensinar. O ensinar requer deixar aprender e isso requer aprender a deixar aprender, pois esse deixar aprender não pode ser uma omissão ou passividade, mas sim dar coordenadas ao discente para que esse venha ter uma 


\section{Wusm Autlatha}

ISSN: 1984-6444 | http://dx.doi.org/10.5902/1984644437922

atitude capaz de aprender de forma autônoma. Ao fazer e permitir que o discente encontre seu próprio caminho ao aprender o docente também passa a ter conhecimento do caminho trilhado pelo discente, por tê-lo acompanhado nessa busca e trajetória o que lhe proporciona o privilégio de aprender sempre e mais que os seus discentes.

Assim em que a partir de um direcionamento, o discente esteja em uma posição na qual se permita aprender. Enquanto que o mérito do docente, longe de estar na obtenção e transmissão didática de um grande conhecimento, está em fazer/deixar o discente encontrar seu próprio caminho ao aprender. Esse êxito resulta na obtenção de conhecimento, por ter acompanhado o seu discente na busca do conhecimento. (KAHLMEYER-MERTENS, 2008). Acreditamos que as contribuições da filosofia de Martin Heidegger são importantes para pensarmos em uma educação que vise um processo de ensino e aprendizagem que seja significativo tanto para o discente quanto para o docente.

\section{Conclusão}

Heidegger retoma o princípio matemático no seu sentido grego, verificando que ele "[...] é a posição-de-fundo em relação às coisas na qual as coisas se nos propõem, a partir do modo como já nos foram dadas, tem de ser dadas e devem ser dadas. O matemático é, portanto, o pressuposto fundamental do saber acerca das coisas" (HEIDEGGER, 1992, p. 82).

Esta retomada nos proporciona pensar acerca do ensino e da aprendizagem de uma maneira autêntica em que ao se ensinar também se aprende e ao se aprender também se ensina. O que implica em um processo de ensinoaprendizagem que não pode ser compreendido de maneira unilateral. Ao despertar no aluno um sentido para sua aprendizagem implica aí que o que será apreendido tenha significância e necessidade a ser reconhecida pelo aluno, ao mesmo tempo em que o aluno trilhará em busca dessa significância e necessidade levará consigo o professor que a todo momento deverá estar aberto a aprender através do trilhos percorridos por seu aluno. 


\section{TH Wu Eutoabुa}

ISSN: 1984-6444 | http://dx.doi.org/10.5902/1984644437922

Destarte, a partir de um direcionamento em que o discente esteja em uma posição na qual se permita aprender. Enquanto que o mérito do docente, longe de estar na obtenção e transmissão didática de um grande conhecimento, esteja em fazer/deixar o discente encontrar seu próprio caminho ao aprender. Acreditamos com isso, que as contribuições da filosofia de Martin Heidegger são importantes para pensarmos em uma educação que vise um processo de ensino e aprendizagem que seja significativo tanto para o discente quanto para o docente.

\section{Referências}

HEIDEGGER, Martin. Que é uma coisa? Doutrina de Kant dos Princípios Transcendentais. Trad. Carlos Morujão. Lisboa: Edições 70, 1992.

HEIDEGGER, Martin. Sobre o humanismo. Trad. de Emmanuel Carneiro Leão. Rio de Janeiro: Edições Tempo Brasileiro LTDA, 1995.

HEIDEGGER, Martin. Introdução à filosofia. Trad. de Marco Antônio Casanova. São Paulo: Martins Fontes, 2008a.

HEIDEGGER, Martin. A teoria platônica da verdade. In: HEIDEGGER, Martin. Marcas do caminho. Trad. de Enio Paulo Giachini e Ernildo Stein. Petrópolis: Vozes, 2008b. (p. 215/250). (Coleção Textos Filosóficos).

HEIDEGGER, Martin. O que quer dizer Pensar? In: HEIDEGGER, Martin. Ensaios e conferências. Tradução de Emanuel Carneiro Leão, Gilvan Fogel, Maria Sá Cavalcante Schuback. 2ª ed. Petrópolis: Vozes, 2001. (p. 111/124).

HEIDEGGER, Martin. Ser e tempo. Trad. Fausto Castilho. Petrópolis: Vozes, 2011.

KAHLMEYER-MERTENS, Roberto S. Heidegger \& a Educação. Belo Horizonte: Autêntica Editora, 2008.

KOHANSKI, Alexander S. The Greek Mode of Thought in Western Philosophy. London: Associated University Press, 1984.

NUNES, Benedito. Passagem para o poético (Filosofia e poesia em Heidegger). São Paulo: Editora Ática S.A. 2. ${ }^{a}$ Edição, 1992.

QUAY, John. Education, Experience and Existence: Engaging Dewey, Pierce and Heidegger. New York: Routledge, 2015.

REZENDE, Antonio Muniz de. Concepção Fenomenológica da Educação. São Paulo: Cortez/Autores Associados, 1990. 


\section{educação revista IFSM \\ 7 1SSN: 1984-6444

ISSN: 1984-6444 | http://dx.doi.org/10.5902/1984644437922

RÜDIGER, Francisco. Martin Heidegger e a questão da técnica: Prospectos acerca do futuro do homem. Porto Alegre: Sulina, 2006.

VEIGA, Itamar Soares. O confronto de Heidegger com o "motivo matemático" da metafísica moderna. Petrópolis: Synesis: Revista do Centro de Teologia e Humanidades. Vol. 3, № 2 (2011) p. 36-52,. ISSN 1984-6754. Disponível em: https://digitalis.uc.pt/en/node/101371. Acesso em: 5 fev. 2019.

\section{Correspondência}

Adma Emanuelle Gama - Universidade Federal De Alagoas - Av. Lourival Melo Mota, S/N, Tabuleiro do Martins Cep: 57072-970, Maceió, ALAGOAS, Brasil.

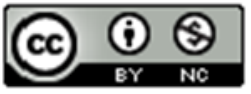

This work is licensed under a Creative Commons Attribution-NonCommercial 4.0 International (CC BY-NC 4.0)

\section{Notas}

\footnotetext{
${ }^{1}$ [...]enfatiza especificamente a importância da noção fenomenológica da verdade como desconhecimento ou falta de visibilidade. Com a questão da verdade do ser, Heidegger pergunta além das análises análogas do aberto significativo do Dasein para abordar o desconhecimento ou abertura desse aberto. (QUAY, 2015, p. 128 tradução nossa).

2 Ereignis: usado por Heidegger para denominar um acontecimento; deriva de sich ereignen, "acontecer, ocorrer".

${ }^{3}$ No estado da physica, as coisas são conhecidas como estão sob condições naturais de observação: forma e conteúdo são considerados juntos como uma realidade objetiva. No poiounema, o conteúdo é uma coisa natural, mas a forma é feita pelo homem. No chremata, o conteúdo predomina na medida em que é um objeto de uso. No pragmata, a forma se destaca como atividade humana, mas lida com um conteúdo para fins práticos ou contemplação. Em todos esses quatro estados, uma coisa é delimitada objetivamente quanto à sua forma e conteúdo, a princípio indiferenciada, mas depois diferenciada em vários graus. No último estado, isto é, na mathemata ou axiomata, as coisas perdem inteiramente seu conteúdo e a mente humana está preocupada com formas puras inter-relacionadas entre si. Esse tipo de conhecimento das coisas é racional no mais alto grau, especialmente quando as relações são expressas em declarações de proporções numéricas, que é a principal característica do raciocínio da ciência moderna (KOHANSKI, 1984, p. 126, tradução nossa).
} 